Case Report:

\title{
Osteoid Osteoma of the Lumbar Spine in a 3.5-Year- Old Boy
}

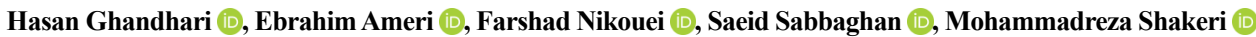

1. Bone and Joint Reconstruction Research Center, Shafa Orthopedic Hospital, Iran University of Medical Sciences, Tehran, Iran.

\begin{tabular}{|l|l|}
\hline $\begin{array}{l}\text { Use your device to scan } \\
\text { and read the article online }\end{array}$ & $\begin{array}{l}\text { Oltation Ghandhari H, Ameri E, Nikouei F, Sabbaghan S, Shakeri MR. Osteoid Osteoma of the Lumbar Spine in a 3.5-Year- } \\
\text { Old Boy. Journal of Research in Orthopedic Science. 2019; 6(3):31-36. http://dx.doi.org/10.32598/JROSJ.6.3.31 }\end{array}$ \\
\hline
\end{tabular}

\section{(c) (1) (\$)}

Article info:

Received: 25 Jan 2019

Revised: 26 Jan 2019

Accepted: 13 Jul 2019

Available Online: 01 Aug 2019

Keywords:

Osteoid osteoma, Spine,

Children, Differential

diagnosis

\begin{abstract}
A B S T RA C T
Introduction: Osteoid osteoma is the third most common benign tumor of bone. The incidence of osteoid osteoma in the spine, particularly in the patients younger than five years, is low.

Case Presentation: Here, we report a case of osteoid osteoma located in the Lumbar Spine (L5) occurred in a 3.5-year-old boy. The patient was referred with a chief complaint of back pain for six months that was aggravated at nights. Furthermore, no apparent spinal deformity existed. Based on the clinical and imaging findings, the diagnosis of osteoid osteoma was made, and the surgical excision of the lesion was performed. The histologic examination of the extracted tissue confirmed the diagnosis of osteoid osteoma.

Conclusions: The back pain alleviated the day after the operation, and he was event-free over 6-month follow-up visits. This report highlights the importance of osteoid osteoma in the differential diagnosis of spinal pain presented at any age.
\end{abstract}

\section{Introduction}

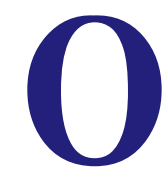

steoid osteoma is the third most common benign tumor of bone, consisting of osteoid and woven bone surrounded by a reactive sclerotic bone with an average nidus size of less than $1.5 \mathrm{~cm}$. It generally affects adolescents and young adults, and its occurrence is rare in people younger than five or older than 40 years. Pain is the main clinical symptom of the lesion aggravated at nights and alleviated with salicylic acid or other Non-steroidal Anti-inflammatory Drugs
(NSAID). Complete operative resection, without any complementary therapies, is the treatment of choice for osteoid osteoma [1].

Osteoid osteoma of the spine is less frequent and accounts for only (10\%) of the cases [2]. Painful scoliosis is prevalent in spinal osteoid osteoma, and (70\%) of the cases complain of it. Soft tissue changes are also quite frequent and may lead to the misdiagnosis, or delay in the right diagnosis [3]. Pourfeizi et al. have reported misdiagnosis rate as $(54.5 \%)$ [4]. The delayed diagno-

\section{* Corresponding Author:}

Mohammadreza Shakeri, PhD

Address: Bone and Joint Reconstruction Research Center, Shafa Orthopedic Hospital, Iran University of Medical Sciences, Tehran, Iran.

Phone: +98 (21) 33542041

E-mail: mshakeri3116@gmail.com 

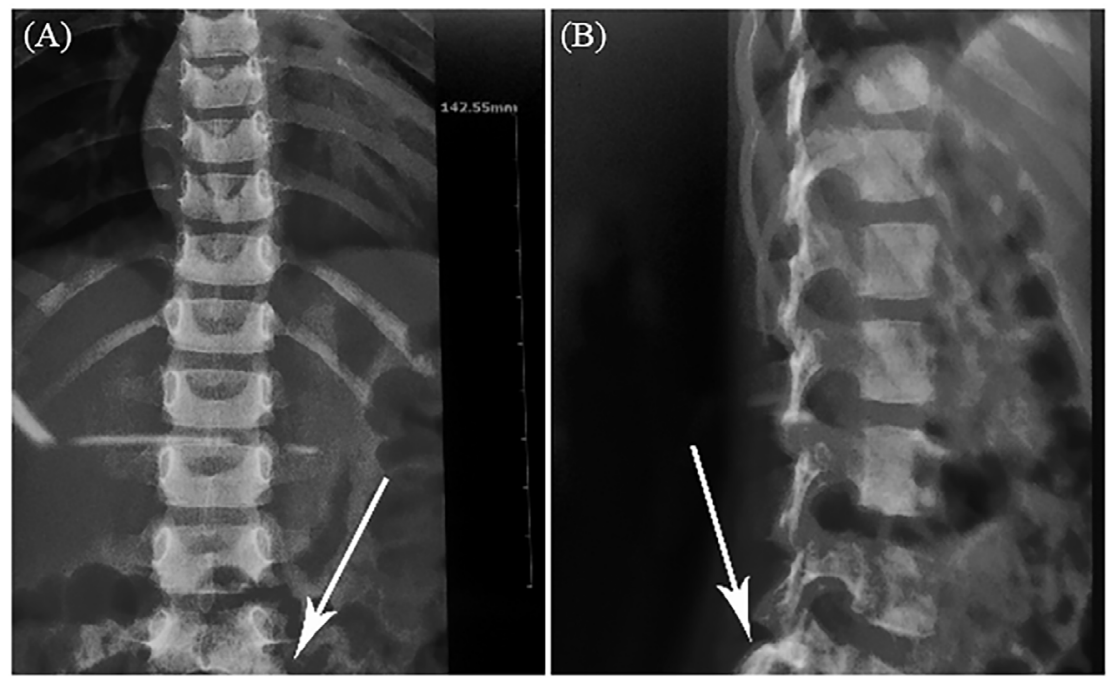

Figure 1. Radiographs of sclerotic area located at the left side of L5 vertebra

A: Anteroposterio; B: Lateral

sis was remarkable in the report of Etemadifar et al. too (mean 15.1 months) [5].

Here, we present the clinical and imaging characteristics of a rare case of osteoid osteoma in the lumbar spine of a 3.5-year-old child, who was treated with surgical excision. Reporting this case is valuable because the presentation of osteoid osteoma is rare in the patients younger than five years, particularly in the spine.

\section{Case presentation}

A 3.5-year-old child was referred to our center with a 6-month history of pain at the lumbar spine aggravating at nights. His back pain severity was independent of daily activities and had no impact on his physical performances. Previous investigations in other centers were in- conclusive. Initial clinical assessments revealed no sign of spinal deformity, including scoliosis or kyphosis. The results of neurologic examinations and laboratory tests were typical. Subsequently, we ordered imaging studies, including plain radiography, Computed Tomography (CT) scan, MRI, and bone scan.

The careful inspection of plain radiographs revealed an abnormal halo as the sclerotic area located at the left side of the L5 vertebra (Figure 1). In addition, there was no radiographic spinal deformity. On the axial and sagittal CT images, the same sclerotic area with a nidus was detected at the left side of L5 vertebra, adjacent to the superior facet of the L5 vertebra (Figure 2). On the T2-weighted MRI, a hyperintense signal was present at the lamina and left superior facet of the L5 vertebra as a result of medullo-trabecular edema, indicating a vas-
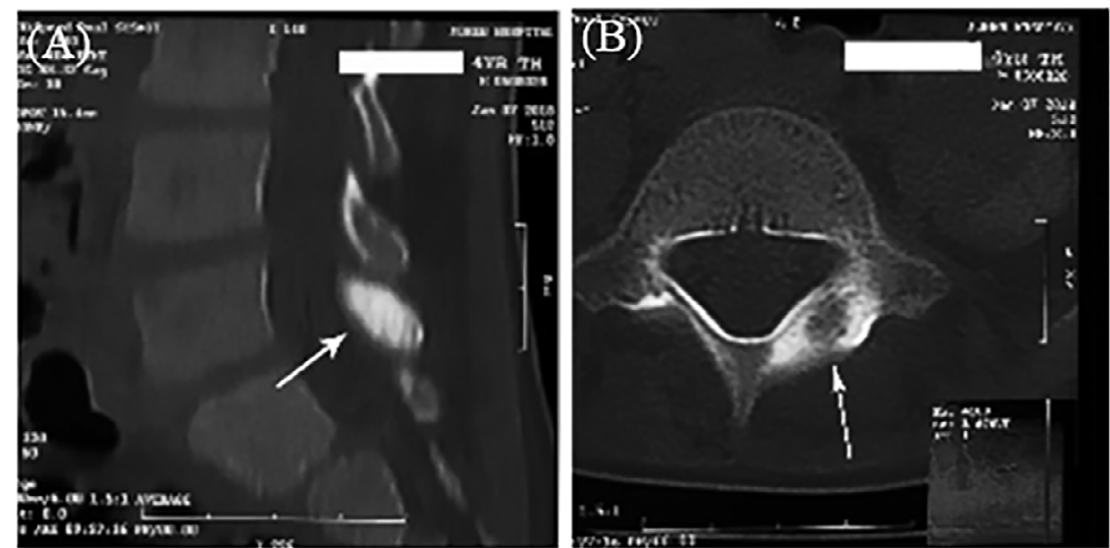

Figure 2. CT images of sclerotic area with a nidus at the left side of L5 vertebra

A: Sagittal; B: Axial 


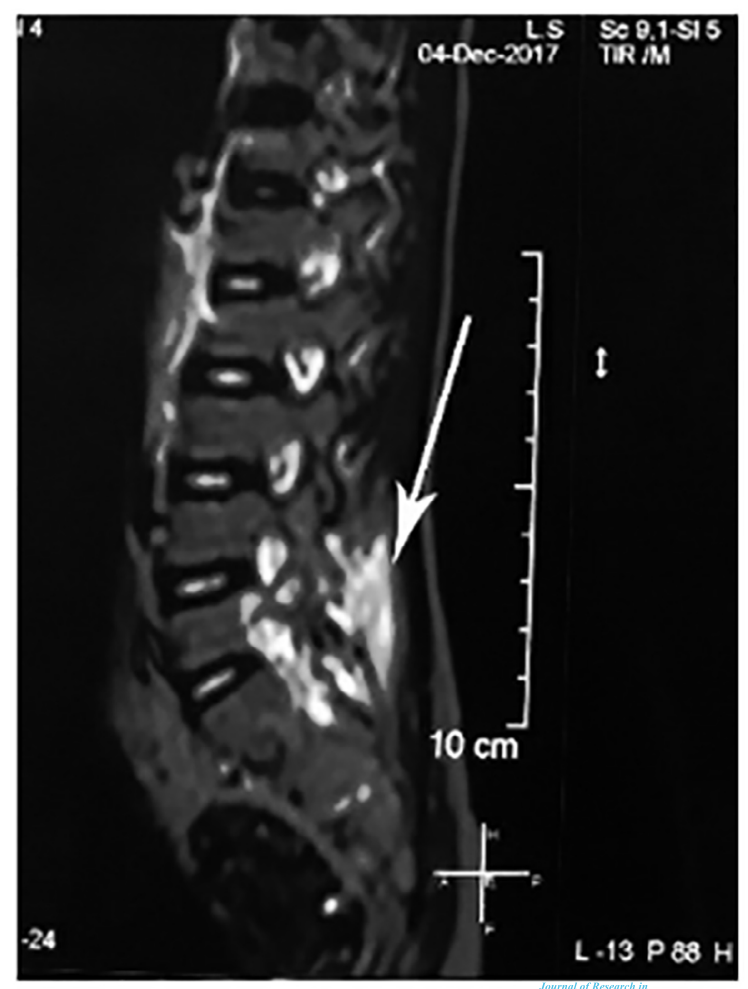

Orthopedic Science Figure 3. T2-weighted MRI showing a hyperintense signal at the lamina and left superior facet of the L5 vertebra.

cularized nidus (Figure 3). The whole body bone scan illustrated an increased uptake at the posterior elements of the left L5 vertebra (Figure 4).

Based on the imaging and clinical findings, the diagnosis of osteoid osteoma was made, and the operative resection of the lesion was planned. Under general anesthesia and prone position, the L5 vertebra was carefully inspected, and the lesion was precisely located using $\mathrm{C}$-arm fluoroscopy. Then, through a posterior midline incision, the patient's skin was opened, his fascia was split, and paraspinal muscles were retracted to expose the L5 vertebra. The sclerotic bone was observable

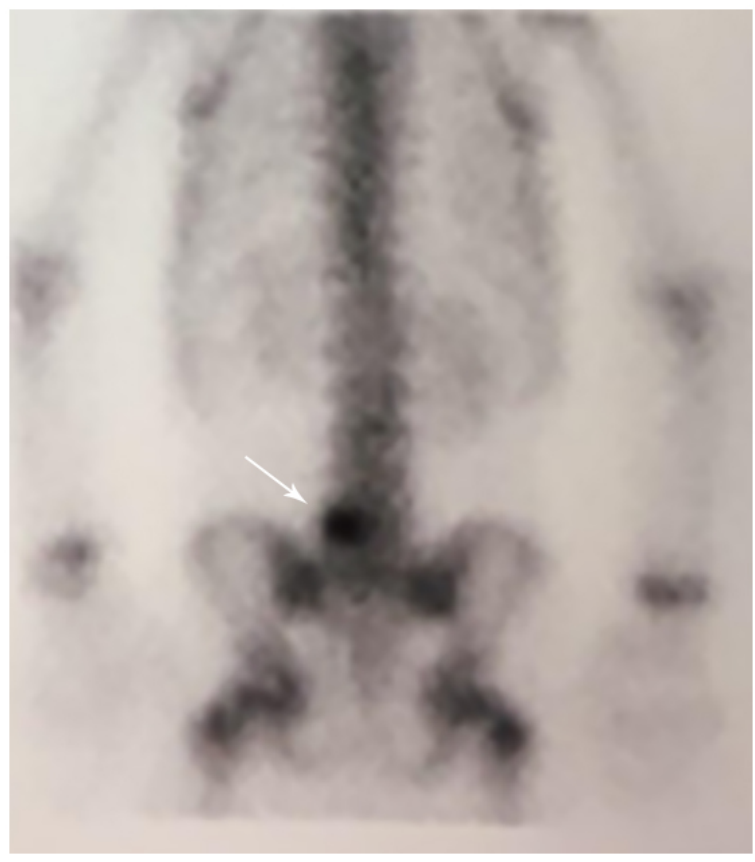

Orthopedic Science Figure 4. Bone scan showing an increased uptake at the posterior elements of left L5 vertebra.

grossly at the site of the lesion. The nidus was excised intralesionally and sent to the pathologic department for histologic analysis. The operation ended with suturing the fascia and the skin.

The pathologic results reported a $(0.2 \times 0.5 \times 0.5 \mathrm{~cm})$ lesion with an anastomosing state from a thin layer of spongy bone; it contained woven bone tissue with the various amount of calcification, surrounded by a loose vascular connective tissue. Osteoblastic and osteoclastic rimming was also noticeable. Altogether, the pathologic findings confirmed the diagnosis of osteoid osteoma (Figure 5).

The day after the operation, the patient's back pain was relieved. The patient was discharged afterward. Over the
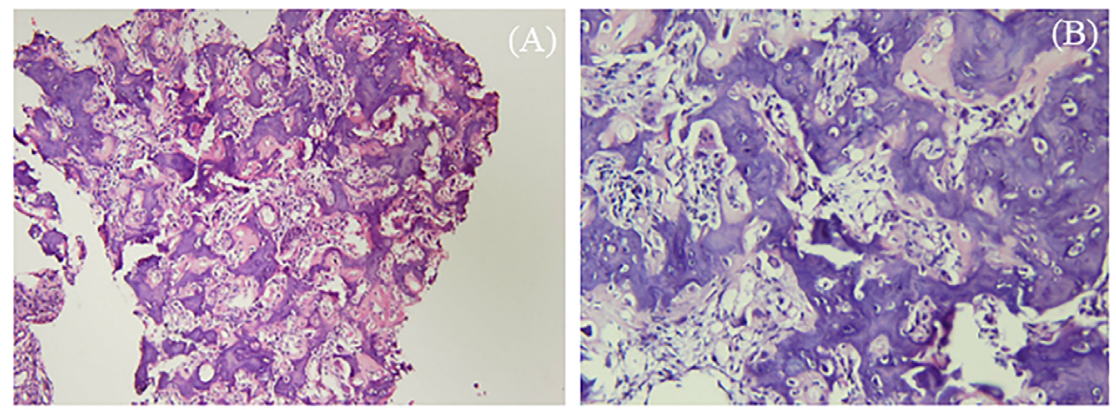

Orthopedic Science

Figure 5. Histologic slides showing woven bone tissue to various amount of calcification, surrounded with a loose vascular connective tissue

A: 10X magnification; B: 20X magnification 
six-month follow-up period, the patient was still painfree, and the patient or his family reported no complaint.

\section{Conclusions}

Osteoid osteoma has rarely been reported in children younger than five years. Ekstrum et al. reported a case of osteoid osteoma in the left femur of a one-year-old boy that was operated successfully [6]. Leicester and Trantalis reported a case of tibial osteoid osteoma in an 18-month-old girl [7]. Thiagarajan et al. also reported a case of femoral osteoid osteoma in a three-year-old boy, who was misdiagnosed as the sclerosing osteomyelitis of the femur [8]. Cotta et al. described a case of osteoid osteoma in an 11-month-old boy with claudication, right-side lower limb shortening, and painless right-side leg volume increase [9]. To the best of our knowledge, no case of spinal osteoid osteoma has been reported in patients younger than five years.

In this report, we described a case of osteoid osteoma at the lumbar spine of a 3.5-year-old boy that was managed successfully with the resection of the lesion. Although the diagnosis of spinal osteoid osteoma is equivocal, the careful examination of clinical and imaging workouts usually leads to the timely diagnosis of the case [3]. The histologic examination confirmed the diagnosis in our case, and his irritating back pain disappeared dramatically after the operation as was anticipated.

Other therapeutic alternatives have also been introduced for the treatment of osteoid osteoma. A success rate of $(94 \%)$ has been reported for radiofrequency thermal ablation [10]. However, the recurrence rate of this method is slightly higher than open operation, although not statistically significant (12-9\%) [11]. Later, Hadjipavlou et al. and Samaha et al. suggested radiofrequency coagulation as a safe and effective treatment for osteoid osteoma, even those adjacent to neural structures $[12,13]$.

Percutaneous interstitial laser photocoagulation is another minimally-invasive technique, in which the nidus is destroyed thermally. A success rate of (95\%) has been reported for this technique [14]. Leicester and Trantalis treated osteoid osteoma, using oral naproxen for four years and five months in an 18-month-old girl presented with mild deformity of the right leg and limping [7].

The study of Ilyas and Younge revealed that medical treatment could control the pain of all patients successfully and suggested non-operative therapy for all patients, reserving operation for those who are unable or unwilling to take NSAIDs [15]. However, there is no consensus on this approach, and further evidence is required before the pharmacologic management of osteoid osteoma is recommended for routine clinical workouts [16].

The main differential diagnosis of osteoid osteoma is osteoblastoma, while osteoid osteoma is generally smaller than $1.5 \mathrm{~cm}$ in diameter and osteoblastoma is larger. Besides, osteoblastoma is less painful, and when the pain is present, it is not as severe as osteoid osteoma and does not aggravate at night. Moreover, osteoblastoma pain usually does not respond to salicylate treatment. Other differential diagnoses of osteoid osteoma are giant cell tumor of bone, aneurismal bone cyst, facet joint diseases, degenerative disc disease, and spondylolysis. Particularly, spondylolysis may be easily confused with osteoid osteoma. However, perilesional bone edema is not distinctive on the MRI of the spondylolysis [3].

In conclusion, osteoid osteoma of the spine could affect people at any age, and the diagnosis might be complicated if sufficient imaging evidence is not obtained. Therefore, the orthopedic surgeon should be aware of the possibility of osteoid osteoma in the patients complaining of persistent spinal pain, even in young children.

\section{Ethical Considerations}

\section{Compliance with ethical guidelines}

The patient provided written consent to use his medical files for publication.

\section{Funding}

This research did not receive any specific grant from funding agencies in the public, commercial, or not-forprofit sectors.

\section{Authors' contributions}

All authors contributed in preparing this article.

\section{Conflict of interest}

The authors declared no conflict of interests. 


\section{References}

[1] Kitsoulis P, Mantellos G, Vlychou M. Osteoid osteoma. Acta Orthop Belg. 2006; 72(2):119-25. [PMID]

[2] Zileli M, Çagli S, Basdemir G, Ersahin Y. Osteoid osteomas and osteoblastomas of the spine. Neurosurg Focus. 2003; 15(5):1-7. [DOI:10.3171/foc.2003.15.5.5]

[3] Guzey FK, Eren B, Tufan A, Aktas O, Tas A. Spinal osteoid osteoma associated with soft tissue changes as a challenging diagnosis: A review of the literature. Shafa Orthop J. 2016; 3(1):e4903. [DOI:10.17795/soj-4903]

[4] Pourfeizi HH, Tabrizi A, Bazavar M, Sales JG. Clinical findings and results of surgical resection of thoracolumbar osteoid osteoma. Asian Spine J. 2014; 8(2):150-5. [DOI:10.4184/ asj.2014.8.2.150] [PMID] [PMCID]

[5] Etemadifar MR, Hadi A. Clinical findings and results of surgical resection in 19 cases of spinal osteoid osteoma. Asian Spine J. 2015; 9(3):386-93. [DOI:10.4184/asj.2015.9.3.386] [PMID] [PMCID]

[6] Ekström W, Söderlund V, Brosjö O. Osteoid osteoma in a 1-year-old boy-a case report. Acta Orthop. 2006; 77(4):686-8. [DOI:10.1080/17453670610012809] [PMID]

[7] Leicester AW, Trantalis JN. Osteoid osteoma in a young child: Successful non-operative management. ANZ J Surg. 2001; 71(8):491-3. [DOI:10.1046/j.1440-1622.2001.02171.x]

[8] Thiagarajan P, Camina P, De Das S, Bose K. Osteoid osteoma in a three-year-old child--a case report. Ann Acad Med Singapore. 1996; 25(5):769-70. [PMID]

[9] Cotta A, Castro RC, Paim JF, Fiuza LS, Lyra MH. Limb length discrepancy on an 11-month-old boy with Osteoid Osteoma. Rev Bras Ortop. 2019; 54(2):210-3. [DOI:10.1016/j. rboe.2017.11.001]

[10] de Berg JC, Pattynama PM, Obermann WR, Bode PJ, Vielvoye GJ, Taminiau AH. Percutaneous computed-tomography-guided thermocoagulation for osteoid osteomas. Lancet. 1995; 346(8971):350-1. [DOI:10.1016/S01406736(95)92228-8]

[11] Rosenthal DI, Hornicek FJ, Wolfe MW, Jennings LC, Gebhardt MC, Mankin HJ. Percutaneous radiofrequency coagulation of osteoid Osteoma compared with operative treatment. J Bone Jt Surg. 1998; 80(6):815-21. [DOI:10.2106/00004623-199806000-00005] [PMID]

[12] Hadjipavlou AG, Lander PH, Marchesi D, Katonis PG, Gaitanis IN. Minimally invasive surgery for ablation of osteoid osteoma of the spine. Spine. 2003; 28(22):E472-7. [DOI:10.1097/01.BRS.0000092386.96824.DB] [PMID]

[13] Samaha EI, Ghanem IB, Moussa RF, Kharrat KE, Okais NM, Dagher FM. Percutaneous radiofrequency coagulation of osteoid Osteoma of the "neural spinal ring". Eur Spine J. 2005; 14(7):702-5. [DOI:10.1007/s00586-004-0865-3] [PMID] [PMCID]

[14] Gangi A, Dietemann J-L, Gasser B, Mortazavi R, Brunner $\mathrm{P}$, Mourou MY, et al. Interstitial laser photocoagulation of osteoid osteomas with use of CT guidance. Radiol. 1997; 203(3):843-8. [DOI:10.1148/radiology.203.3.9169714] [PMID]

[15] Ilyas I, Younge DA. Medical management of osteoid osteoma. Can J Surg. 2002; 45(6):435-7. [PMID] [PMCID]
[16] Clayer M. Osteoid osteoma in a young child: Successful non-operative management. ANZ J Surg. 2002; 72(2):168. [DOI:10.1046/j.1445-2197.2002.2327a.x] [PMID] 
This Page Intentionally Left Blank 